\title{
The law and economics of environmental taxation: when should the Ecotax kick in?
}

Citation for published version (APA):

Backhaus, J. G. (1998). The law and economics of environmental taxation: when should the Ecotax kick in? METEOR, Maastricht University School of Business and Economics. METEOR Research Memorandum No. 017 https://doi.org/10.26481/umamet.1998017

Document status and date:

Published: 01/01/1998

DOI:

10.26481/umamet.1998017

Document Version:

Publisher's PDF, also known as Version of record

\section{Please check the document version of this publication:}

- A submitted manuscript is the version of the article upon submission and before peer-review. There can be important differences between the submitted version and the official published version of record.

People interested in the research are advised to contact the author for the final version of the publication, or visit the DOI to the publisher's website.

- The final author version and the galley proof are versions of the publication after peer review.

- The final published version features the final layout of the paper including the volume, issue and page numbers.

Link to publication

\footnotetext{
General rights rights.

- You may freely distribute the URL identifying the publication in the public portal. please follow below link for the End User Agreement:

www.umlib.nl/taverne-license

Take down policy

If you believe that this document breaches copyright please contact us at:

repository@maastrichtuniversity.nl

providing details and we will investigate your claim.
}

Copyright and moral rights for the publications made accessible in the public portal are retained by the authors and/or other copyright owners and it is a condition of accessing publications that users recognise and abide by the legal requirements associated with these

- Users may download and print one copy of any publication from the public portal for the purpose of private study or research.

- You may not further distribute the material or use it for any profit-making activity or commercial gain

If the publication is distributed under the terms of Article $25 \mathrm{fa}$ of the Dutch Copyright Act, indicated by the "Taverne" license above, 
revised, 17 September 1998

The Law and Economics of Environmental Taxation: When Should the

Ecotax Kick In? ${ }^{1}$

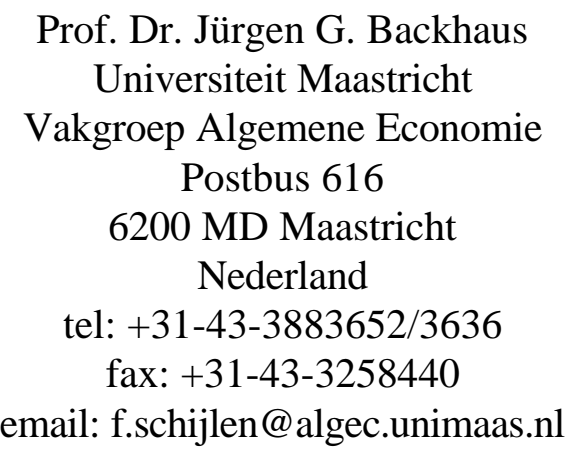

1 Comments from two anonymous referees and the editors are gratefully acknowledged. 


\section{The Law and Economics of Environmental Taxation: When Should the Ecotax Kick in?}

Ecological taxes are categorically different from the classical taxes which seek to extract a certain revenue at a minimum excess burden. Classical taxes are levied so as to interfere with the market based allocation of recourses as little as possible. Ecological taxes, on the other hand, are designed to achieve a well defined ecological effect again at a minimum of excess burdens. The revenue of an ecological tax, however, is coincidental and nil when the tax is ecologically optimal. Most ecological taxes currently proposed are not ecologically optimal as defined here. In generating revenues they partly miss the ecological objective. The tax revenue is an indication that the ecologically relevant decisions of some agents in the jurisdiction have not been affected so as to achieve the desired ecological result.

This paper explores the law and economics of ecological taxation from this point of view. The question is: how can an optimal ecological tax be institutionally structured so as to have a maximum impact on ecologically relevant decisions in the desired scope and direction? The paper systematically explores and applies James M. Buchanan's Cost and Choice: An Inquiry in Economic Theory (Chicago: Markham, 1969) to this question and derives an innovative institutional solution.

Key words: choice influencing taxes, ecological taxation, environmental taxation, opportunity cost, global warming, carbon fuel consumption, regulatory decisions under uncertainty.

J.E.L. codes: H21, K34, Q28, 38 


\section{The Law and Economics of Environmental Taxation: When Should the Ecotax Kick In?}

In this essay, it is being argued that environmental taxes are fundamentally different from traditional taxes. They are not primarily designed to be revenue raising instruments, nor are they regulatory taxes in the sense of accomplishing slight changes in individual or firm behaviour. The point of environmental taxation and of designing an environmentally sound tax system is rather to accomplish deep and structural changes in the economic and ecological behaviour of individuals, households and firms, i.e. changes of patterns and not changes of degree. When these basic patterns of behaviour and processes are to be influenced, it is important to identify those basic aspects that are environmentally and ecologically important and susceptible to change as a consequence of a tax intervention. Consequently, one has to identify those instances where basic choices can be taken and where decision makers face alternatives among which they can choose.

This approach is different from the standard approach to discussing environmental taxation. The law and economics approach pursued in this essay looks at structural changes and the possibility of effecting such changes through tax instruments. The standard approach to ecological taxation is to impose regulatory taxations so as to curtail environmentally and ecologically undesirable effects and thereby even generate a double dividend consisting of on the one hand the improvement of the environment and the ecological system and on the other hand a revenue which can be used for different policy ends, such as those relating to the environment and the ecological system. Taxes which promise to generate such a double dividend are, of course, politically very attractive. It has, however, repeatedly been pointed out that the double dividend approach is basically flawed (Backhaus (1995), Schneider and Volkert (1996) ). After initial enthusiasm on the part of politicians and policy advisors, the consensus has now vanished and it has even been suggested that the double dividend be negative. (Bovenberg and de Mooij, 1994)

With so much ambiguity surrounding one of the core concepts of environmental taxation, a fresh approach may well be tried. This essay first looks at central features of the double dividend approach from a law and economics point of view. It then explores a Coasian perspective in order then to proceed to an analysis based on a rigorous application of Buchanan's cost and choice concept. A fourth section contains a simple illustration. The essay concludes with a summary and an emphasis on unresolved issues. ${ }^{2}$

\section{The Double Dividend}

The case for the double dividend in specific forms of environmental taxation has for instance been made by Pearce, 1991, with an application to carbon taxes. Although many different formulations are possible, and the double dividend can be derived in different ways, the standard approach relies on a scenario where in a particular fiscal entity tax rates are high and

\footnotetext{
2 Parts II-IV can be read after skipping part I.
} 
allocative distortions are substantial to the point that governments feel an urge to reduce the excess burden without reducing public spending. If in such a scenario a tax can be levied on an environmentally damaging input such as carbon fuel, the demand for which is highly in- elastic, the excess burden of that carbon tax will be low, and the revenue can be used in order to substitute for the revenue derived from those taxes which can only be imposed with a high excess burden. The double dividend then appears on the one hand in addressing an environmental problem (an externality), in generating a substantial revenue at low cost to the economy and in consequently reducing excess burdens from taxes that meet high levels of resistence.

In order to understand the context in which the notion of the double dividend became prominent and from which policy advise has often been extracted without properly noting this context, let us quote from Pearce, (1991:938) "who sets out those conditions. These are:

a: That if warming occurs it will impose significant damage;

b: That the damage is irreversible;

c: That the initial cost of controlling greenhouse gas emissions are low;

$\mathrm{d}$ : That greenhouse gas controls bring incidental or joint benefits besides the containment of global warming."

The incidental benefits warrant closer mention. "The two basic technological responses are a. substitution of low carbon fuels for high carbon fuels (for instance natural gas for coal, nuclear energy, or both) and

b. energy conservation in the sense of reductions in the ratio of carbon based energy to economic activity. Both technological responses have the effect of reducing "conventional" air pollutants, such as nitrogine oxydes, sulfor oxydes and suspendent particulates (dust and smoke)." (Pearce, 1991:939). The context of the debate is then adequately described like this: "This combination of uncertainty, irreversibility, probable initial low control costs, possible very high damage costs in the absence of action, and potentially high joint benefits from control, suggest that the policy stance on global warming should be fairly aggressive". (Pearce, 1991:939).

To understand the astonishing degree of disagreement among economists and policy makers with respect to global warming that has recently erupted ${ }^{3}$ one should appreciate the particular framing of the debate. Goulder (1994) remarks in his "Reader's Guide": "thus the debate about the double dividend reflects the desire to be able to make safe judgements about environmental reforms in the presence of uncertainty". ${ }^{4}$ The situation is reminiscent of the strategy used by Kaldor and Hicks when they were looking for a normative anchor on which to hang their modern approach to welfare economics. When looking at a particular policy proposition, the

$3 \quad$ Frederick Seitz, “A Major Deception on 'Global Warming"', Wall Street Journal Europe, June 20, 1996 and "Letters to the Editor": "Cover-up in the Greenhouse?", August 6, 1996.

4 Quoted after Bohm, 1996, p. 4. The original quote is L. Goulder, "Environmental Taxation and the "Double Dividend". A Reader's Guide". Paper presented at the International Institute of Public Finance, 50th congress, Cambridge, Massachussets, August 23-25, 1994, also in NBER working paper, nr. 4896. 
Pareto principle should be invoked as if it were unknown who the beneficiaries of that policy would be and who would be harmed. It should be sufficient to satisfy the compensation possibility criterion, i.e. the total benefits summed over all individuals should outweigh the total costs summed over all individuals, so that in principle, the former could compensate the latter. The reason for this approach, which denies the existence of well established property rights and legitimate expectations on which investment decisions are being based, was the notion that in the long run and with a consistent application of this principle, the distribution of costs and benefits would be uncertain and hence likely an even one so as to provide for a net benefit to all, not of any particular policy measure, but of the adoption of the policy rule.

\section{A Coasian View}

Against this reasoning, which, in fact, underpins the entire edifice of modern welfare economics, Ronald Coase has consistently argued with respect to the special case of externalities that such externalities merely reflect the existence of incompatible uses of the same resources by different agents. In the presence of well established property rights, and in the absence of significant transactions costs, externalities cannot persist since the right of use will be appropriated by that actor with the highest willingness to pay or, alternatively speaking, he who experiences the highest cost from an externality will seek to contain those costs by either establishing his property rights over the entire range of resource uses or else by trying to recover as large a compensation as possible from the sale of his rights of usage.

By way of example, consider a coal based electricity generation plant located in a valley close to a river from which it can take cold water for its cooling tower, which it partly re-emits into the river and partly into the air. Assume further that, next to the warming effect, there is no further contamination of the water which is being re-introduced into the local ecological system. In addition, electricity generation by burning coal leads to partly toxic fumes which can be reduced to safe levels by building large smoke stacks and thereby distributing the substance over a large area. The local economy in the ecological system is further assumed to consist of agriculture based production, for the sake of simplicity we assume wine growing on the slopes of the mountain surrounding the river and fishery in the river.

From a physical point of view, there is emittance of fumes into the air, which can be spread over a large area so as to avoid safety problems: there will be a warming of the water and a certain amount of (clean) steam being released into the air. Both a combination of a warmer river and steam in the air are likely to lead to the formation of mist which inhibits sun exposure of the grapes.

From the point of view of the fishery industry, the warming of the river will affect the existing supply of fish. Finally, if additional sources of toxic smoke are located outside our ecological system in question with similar techniques of dispersion, the operation of the carbon based power plant within the system may well lead to unsafe levels of toxic exposure, in the sense that ceasing the operation of the plant would reduce the levels of toxic exposure again to safe levels.

On the basis of these assumptions let us look at the externalities in question from a Coasian 
point of view. The intra-system externalities crucially depend on the number of different uses we allow to be made of the eco-system. We have incompatibilities between the power plant and the wine growing industry, between the power plant and the fishing industry, but no incompatibility between wine growing and fishing - small wonder, since both have probably coexisted for a long period of time with well established property rights governing the use of the river and the surrounding mountain slopes. The negative effects from warming of the river can probably be contained on the part of the fishing industry if there is certainty about the temperature of the water and fish used to higher temperatures can be bread and harvested in that segment of the river. That would, however, imply that the inflow of colder water will now have to be regarded as a negative externality from the point of view of using the river for warmer water fish. Hence, any arrangement as between the fishing industry and the power plant would have to involve garantees and compensation schemes with respect to the temperature of the river. Both the right to bread and harvest fish and the right to emit warm water would have to be curtailed so as to make the two uses of the river compatible. Fishermen would not be allowed to bread and harvest those species of fish that are particularly vulnerable to large fluctuations of water temperature, and in particular vulnerable to excessively low levels of water temperature, because that is most difficult for the power plant to control during the spring season when the ice is melting in the mountains. With respect to these two parties, then, a partitioning of the traditional rights of uses would allow trade and contractual arrangements governing this trade.

With respect to the relationship between the power plant and the wine growing industry, the formation of mist is crucial, which implies that under those weather conditions when mist is crucial (in particular during the early Fall when sun exposure is necessary for the grapes to ripen and mist can lead to the contamination with insects and diseases) the two uses of wine growing and cooling with river water have to be reconciled. Hence, a contractual arrangement needs to be designed that governs the ejection of steam during these sensitive periods: alternative forms of cooling or additional forms of re-cooling the steam before re-emanating it into the river or ejecting it into the air may have to be considered, the timing of ejection or emanation may also be crucial during the day, as for instance late afternoon mist formation on sunny days in unlikely. Again, a partitioning of property rights with respect to the water use including the possibility of mist formation and with particular emphasis on that possibility during crucial periods of growth and harvast will in all likelihood allow for the internalization of the externality through an effective definition of property rights.

The analysis has, so far, been substantially facilitated by limiting the number of alternate and partly incompatible uses of the common resource (the valley with the river) for the three different purposes of energy generation, wine growing and fishing. In addition, the plant emits toxic fumes, which, however, become toxic only if additional sources of emission exist outside the system. Obviously, here a different ecological regime needs to be defined for that particular resource use, which is independent from the other resource uses. It is here where the principle of subsidiarity has to be invoked. ${ }^{5}$ In order to draw the conclusions from the Coasian analysis,

$5 \quad$ See Jürgen Backhaus, "Subsidiarity and Ecologically Based Taxation: Aspirations and Options", in: Sabine Urban (ed.), Europe in Progress, Wiesbaden: Gabler, 1995, pp. 223-264. 
it is interesting to note which decisions need to be affected in order to allow compatible resource use by means of an optimal partitioning of property rights. With respect to the power plant, it is important to recognize the alternate uses in chosing appropriate technologies and modes of operation. On the one hand, with respect to agriculture (wine growing), plant operation needs to take into account weather conditions during particular periods of the year with respect to providing for a containment of the emission of the cooling substance water into both air and river. This may require a different definition of peak times with respect to production, alternate uses of cooling equipment, larger cooling systems so as to have more standby cooling power as well as close monitoring of weather conditions. These decisions, in all likelihood, can be cost effectively taken at the time of plant construction and design. Later, it will likely be more expensive to make alterations or take these conditions into account as constraints on operation. This aspect of the scenario is consistent with the assumptions in the global warming debate, which also contain the notion that an early intervention will lead to lower total costs than a later one.

With respect to the relationship between the power plant and the fishermen, again the management of the emanation and emission of the cooling substance is crucial. Interestingly, here at times a larger inflow of warm water into the river may be required in order to protect the fishing stock from sudden drops in water temperature. As obviously the pattern of breeding and harvesting fish can largely contain the cost of sudden temperature drops, during Winter seasons different fish can populate the river than during Summer seasons, the requirement may only involve relatively small peak periods and, in this case, require the emanation of uncooled water into the river. Again, a large water reservoir and the ability of using and managing different forms of cooling will be required for this approach to be successful. Very similar to the first case, again the cost of operation will largely be affected by the timing of the decisions, and when the decisions can be taken at the time of design and construction of the plant, the costs will in all likelihood be much lower than if later alterations of plant design, process of production or management need to be implemented.

\section{Basing Environmental Taxation on Opportunity Costs}

"The tax which each individual is bound to pay ought to be certain, and not arbitrary. The time of payment, the manner of payment, the quantity to be paid, ought all to be clear and plain to the contributor, and to every other person." ${ }^{6}$ When we deal with effective environmental taxation, every one aspect of this principle, which is part of the traditional canons of taxation, stands to be violated. To see this, we have to invoke the difference between objective costs and subjective or choice influencing costs, that has been effectively introduced into public finance

6 Adam Smith, The Wealth of Nation, book 5, chapter 2, part 2, section 2. London: Dent, 1971, II, p. 306. 
analysis by James M. Buchanan. ${ }^{7}$ Pigou's theory of regulatory taxation ${ }^{8}$, which underlies the current literature on environmental taxation, is based on the notion that the external costs of a particular activity can be internalized into the decision calculus by means of imposing a tax, thereby reducing the externality. This requires, however, that the taxing authority is aware of the costs. This in turn requires the notion that costs can be objectively measured. Costs that can be objectively measured, on the other hand, need not be those that influence decisions. As we have seen in the introductory survey, carbon taxes are supposed to meet an in-elastic demand for carbon fuel, only in the long run leading to the substitution of more energy efficient carbon fuels over less energy efficient ones. Speaking of an in-elastic demand subject to taxation means that the tax does not influence the decisions of the taxee to any large degree. In order to appreciate the breadth of this statement, consider the example used before in the following way. After the electric power plant has been installed and power supplies have been improved for the region, the wine growers suddenly and unexpectedly experience heavy losses due to the formation of mist in the valley. They intervene with the government which proceeds to impose a power penny, i.e. a certain percentage charge on each currency unit billed. The " $x$ " percentage charge, called a power penny in order to emphasize its environmental appeal, is calculated to equal the losses of the wine growers and implemented as an ecological regulatory charge. No doubt, this power penny satisfies Smith's criterion of a certain tax, and it can be readily implemented, since the charge can just be added to the normal bill. Yet, the power penny is unlikely to have any significant effect on the activity of the power plant that causes the externality. Although the vintners may be compensated for the damages they suffer, the economy as a whole still suffers the loss of either less wine production or wine of lower quality or both, while energy will be more expensive for all. Hence, the bundle of products available to consumers in the economy will be smaller with the same money income, the power penny only spreads the externality, it does not internalize it. The power penny, in this sense, is no different from the smoke stack. It just spreads the externality, like a financial equivalent to the physically distributing chimney.

An environmentally and ecologically relevant tax needs to be a tax that affects the choice influencing costs. In designing such a choice influencing environmental tax, we have to look for the time and locus at which environmentally relevant choices are made. Since these choices are not made on any basis of periodicity as a normal tax would require, an incentive needs to be created which triggers the tax. This may sound paradoxical, since a tax is by definition an involuntary payment that for this very reason tends not to be initiated by the entity to be taxed. In the case of environmentally relevant taxes, however, the situation must be different. Neither choice influencing costs, which are subjective, nor locus and time of decision making are directly or indirectly observable by an outside agency, such as a tax authority. In our example,

James M. Buchanan, Cost and Choice: An Inquiry in Economic Theory. Chicago: Markham, 1969.

8 In mentioning Pigou's name, I feel compelled to add that Pigou himself felt corrective taxes to be impossible, as the taxing authority would lack the requisite information. See A.C. Pigou, Socialism vs. Capitalism, London: McMillan, 1947, pp. 40-44: "But the practical difficulty of determining the right rates of bounty and of duty would be extraordinarily great. The data necessary for scientific decision are almost whole lacking". (pp. 42/43). 
the appropriate decisions with respect to the design of the plant, the production process and the management of production with a view to allowing different uses of the same resource can, but need not be taken before production activity actually starts or when new investments are due.

The objective of the tax is to encourage environmentally and ecologically preferable plant design, production processes and production management, but what this design, these processes and the management will be is only known to the decision takers involved, and only after an appropriate decision making process has been launched. This implies that the tax involved can only be of the type of an incentive. If that is the case, however, the question arises as to what might consitute the tax base.

As we noticed above, partitioning of property rights so as to make different resource use compatible in fact moves the production possibility frontier in a north eastern direction. The resulting production potential constitutes a source of earnings for the participants, which in itself constitutes a tax base. When a tax authority tries to encourage the creation of a stream of income in order to broaden the tax base, it can grant deductions as an incentive. Such deductions then can form an appropriate lever to encourage environmentally or ecologically desired changes, which cannot be prescribed but only be triggered by way of incentive. The system then takes on the following form. When a particular project is to be added to an existing eco-system, as in our case the power plant, building and operation permits need to be secured as usual. Similarly, financing will be dependent on these permits. Under the present regime, no particular attempt at redefining property rights through multiple negotiations can be expected. The transactions costs required to lead to an optimal repartitioning of property rights in these cases can be assumed to be substantial. It is here where the ecological tax instrument must provide a lever.

An opportunity for re-negotiating a partitioning of property rights in order to make different uses of the same resource compatible can be created by providing for a tax incentives on the grounds of ecologically desired improvements. If a scheme such as the one outlined in section II can be presented and shown to lead to substantial savings and/or extended production possibilities, an " $x$ " year tax credit for the income generated through the scheme can be granted upon certification by an environmental regulatory authority. The tax credit can, in turn, be used as collateral for the outlays needed in order to facilitate implementation of the agreement arrived at. This solution implies that the information needed for the decision of the tax authority is totally forthcoming from the parties involved and, as it needs to be certified by the environmental regulatory authority and does not require any additional information gathering on the part of the tax authority. The tax credit can easily be implemented within the context of current procedures, and the tax base has been broadened by the volume of the income generated (I) through re-partitioning of property rights multiplied by $(n-x)$, with " $n$ " being the time during which taxes can be expected to be levied.

As we look at Adam Smith's criteria, we notice that this scheme violates every one aspect of his principle of certainty. The tax incentive is not the same for each tax payer, as it crucially depends on the specifics of the re-partitioning scheme negotiated. Although the tax incentive is not arbitrary, it is certainly not well known in advance. The time at which it becomes effective depends only on the activities of the taxees, as does the manner of payment, as even does the quantity to be paid, and none of these is clear and plain in advance. What becomes clear and plain is the tax credit, as this instrument needs to be used as collateral. The tax credit, in turn, 
drives the implementation of the scheme. If the authorities err in setting the tax credit too low, the scheme will not be launched and the additional increase of the tax base will not be forthcoming. If they set it too high, they still increase the tax base but forego some tax revenue.

Ironically enough, this environmental tax as a tax credit satisfies the double dividend criterion. The double dividend even has an institutional realization. The environmental dividend is being certified by the environmental authority, the fiscal dividend is being certified by the tax authority granting the tax credit.

\section{A Simple Illustration}

At the heart of the proposal made in this paper lies Buchanan's notion of choice influencing costs and, specifically choice influencing taxes. The proposal is driven by the need to define a choice influencing tax, since the point of introducing ecological taxes is to influence decision makers in their ecologically relevant behaviour. For purposes of illustration, we have defined the stylized situation of a river valley with three partly incompatible uses of the eco-system, i.e. wine growing, fishing, and power generation. Of course, this is only a stylized model, any degree of complexity can be introduced without affecting the basic issue, which is to define property rights so as to make the different uses of the resource compatible. By repartitioning property rights, the production possibilities of the economy (here in the river valley) are being broadened, but these benefits are partly offset by the transactions costs that need to be incurred in order to bring the new definition of property rights about.

If taxes are to influence choices, it is important to define or identify those decision points where choices can actually be taken. The difficulty with identifying such decision points is that a tax administration cannot by itself accomplish this task. Only a general rule broadly describing the decisions and their consequences will allow the identification of a particular decision point, a point in time which is subject to decisions by the tax payer. This is in itself not an anomaly. In the presence of capital gains taxes, for instance, tax payers will take their decision so as to minimize the liability, they will therefore choose the point of a transaction that leads to a capital gain with a view to minimizing the tax liability. In the case of ecological taxes, we want to stimulate neither capital accumulation nor tax avoidance but a positive ecological decision, which means that an incentive needs to be defined so as to induce parties to change their behaviour in an ecologically positive way. In our stylized example, the decision requires co-operation of the three parties involved, with respect to

a) the choice of technology and process management of power production;

b) the choice of fish to bread and harvest;

c) in all likelihood also the choice of grapes.

The crucial decision involves the consensual repartitioning of property rights in order to make a resource use compatible, and on this repartitioning decision rest the three decisions named above.

An important issue in this case is technology choice. The stylized example involves two different types of technology choice. On the one hand, inside the ecological system as defined in section two, the relevant technology choice refers to the cooling system, which in our example must be flexible enough so as to provide for either warm water directly emitted into 
the river, or water being retained within the cooling system long enough so as to prevent the formation of mist at crucial moments. However, another technology choice is relevant with respect to the ecological system itself and interests outside this system. This is the choice of fuel to be used for the generation of electrical power, such as carbon or nuclear energy.

\section{Issues of Implementation}

This section is devoted to showing the substantial difference between a traditional eco-tax and the environmental tax instrument developed in this paper, which imposes the environmental tax by (seemingly paradoxically) working with the tax credit. Such a comparison, of course, must be a mental exercise, since the new instrument is not yet in place, we cannot conceivably have data on which to base a comparison. Even if we had such data, due to the complexity of how this instrument works, as it affects the behaviour of the respective agents in the long run including the choice of technology, it would be difficult to find proper cases to compare: the number of relevant variables would be large, the time spent over which the comparison would have to be conducted would necessarily have to be a long one and, by implication, the number of intervening variables would also have to be considered high.

On the other hand, such a comparison is necessary in order to gorge the practical feasibility of the proposal. It would be irresponsible to propose a tax instrument with such deep and far flung consequences if we could not at least offer a framework in which to analyze the respective effects of alternative ecological taxes. Such a framework I am trying to offer in this section of the paper.

In developing this framework, I can rely on the traditional theory of taxation, developed already by Adam Smith $^{9}$ and with variations reproduced in every major text book in public finance. I am referring to those criteria by which we judge whether tax is "good" in a very specific sense and should therefore be supported, or whether it fails this test. A tax is, of course, not a good thing as such. Yet when we accept the reason for its existence, such as the need to raise revenues for a particular public purpose or, in this case, to conduct environmental policy, then we can discuss different tax instruments from the point of view of that need in terms of the criteria that follow. In their modern version, we typically distinguish five such criteria or principles which constitute the canon of taxation ${ }^{10}$.

On the other hand, these five criteria can be applied to the conceivable levels or jurisdictions of taxation. In principle, we can distinguish between the federal level in a political entity that is constituted of Member States, a level of the Member States, as well as the original territorial entities, such as a municipality, counties, cantons and the like. Obviously, if a federal system is itself part of a federation, the discussion here offered under the first level of the federal government needs to be repeated twice, once for the overall federation and once for the Member State as a federation. In addition to these three levels of government, the federal, the state and the local level of government, we also have the functional forms of government, which have

$9 \quad$ Adam Smith, The Wealth of Nations, (1786). London: Dent, 1971

10 See for instance, Joseph Stiglitz, Economics of the Public Sector, New York: Norton 
become increasingly important in recent times. These functional forms can be defined differently, functionally or territorially for instance in ecological entities such as a water basin (the Dutch "waterschappen"), a mountain ridge or a sea basin, they can also be without any territorial link, such as when a profession is publicly chartered and has its publicly sanctioned rules and dues. These dues are taxes in our sense. There may be room for an important increase in the role of these entities, as Bruno S. Frey has argued in various papers on the importance of functional overlapping competitive jurisdictions (FOCJ) in a series of papers ${ }^{11}$. This approach yields a five by four matrix, with the five principles of taxation vertically arranged and the four levels of government horizontally enumerated. We shall now discuss the four levels of government in turn, with the five principles as our guiding criteria.

The Matrix of Comparison

\begin{tabular}{|l|l|l|l|l|}
\hline & 1 Federal & 2 State & 3 Local & 4 FOCJ \\
\hline 1 Efficiency & 1 & 6 & 11 & 16 \\
\hline 2 Feasibility & 2 & 7 & 12 & 17 \\
\hline 3 Flexibility & 3 & 8 & 13 & 18 \\
\hline 4 Responsibility & 4 & 9 & 14 & 19 \\
\hline 5 Fairness & 5 & 10 & 15 & 20 \\
\hline
\end{tabular}

1. From the point of view of economic efficiency, here discussed against the background of implementing either set of tax policies at a federal level of government, the following can be said. At the federal level of government, there will be extreme difficulties in collecting the correct information that is necessary for a regulatory ecological charge. This is a problem Pigou already had addressed. ${ }^{12}$ However, the system of ecological taxation operating with tax credits described in this article may very well require a supervisory authority at the federal level in order to make sure that the tax credits are not wasted in that interest groups with local importance do not ride the roost. In this sense, from an efficiency point of view, the federal level of government has a very small role to play with the traditional Pigouvian scenario, a meaningful role, however, with the scenario of choice based ecological taxation.

2. With respect to the feasibility of implementing either proposal at the federal level, it needs to be noted that it is obviously easy to implement an excise tax said to have ecological merits at the highest level of the taxing authority, in this case in the federal level, since in this case, evasion will be reduced to either external markets or intra-

11 See Bruno S. Frey and Reiner Eichenberger, "FOCJ; Creating a Single European Market for Governments", in: Dieter Schmidtchen and Robert Cooter (eds.), Constitutional Law and Economics of the European Union, Cheltenham: Edward Elgar, 1997, pp. 195-215 
jurisdiction tax evasion. The administrative feasibility here stands in stark contrast with economic efficiency, since Pigouvian charges cannot achieve the desired goal. As for choice based ecological taxes, their feasible implementation tends not to be at the federal level, since the federal level is too far removed from the scenario in which choices actually have to take place. From the point of view of the bureaucracy at the federal level, if it were interested in considering this form of tax, the choice based ecological tax is unattractive, since it renderes only a very small role to the federal level of the jurisdiction.

3. With the criterion of flexibility we ask the question whether in this case of the federal level of the jurisdiction, a particular tax regime set in place will automatically and flexibly react to changing circumstances relevant to the object of taxation so as to minimize the excess burden of taxation. Here we can first and foremost note that the Pigouvian regime is totally inflexible with respect to the desired result, as it has no inbuilt corrector to guide people's choices under differing circumstances. This is totally the opposite with the choice based ecological tax instrument, since the tax credit also serves as a burden sharing instrument with respect to the risk of the ecologically friendly investment, in harsh time the tax authority assumes a higher burden of that share, and that is in the interest of tax flexibility. However, the federal level of government is a poor location for assuming this facilitating role, it should rather better serve in a re-assurance capacity for lower levels of government. Lower levels of government can better weigh the economic opportunities faced in a particular region under certain circumstances, as economic development tends to be drastically different from one region to the other, and hence technological choices work out very differently from one region to the other. Since the choice based ecological tax approach imposes a substantial amount of fluctuation in tax revenues on the tax jurisdictions involved, it may be important, from their point of view, to have some burden sharing mechanism as a re-insurance system, and here the federal government might play a useful role.

4. Issues of political responsibility arise when political processes, such as log roling ${ }^{13}$, tend to divert the functional economic purpose of a particular policy measure, for instance through processes of rent seeking. The question here is whether at the federal level of government, either one of the tax regimes discussed in this paper would give rise to such diverting initiatives, and whether at this level of government an effective response mechanism would be in place.

As the Pigouvian regime sets fixed rates per output hinged on particular technology choices, it opens every door for rivals attempts to target particular technologies in their own interest and at their rivals detriment. Once the per unit of output charges are

13 See James M. Buchanan and Gordon Tullock, The Calculus of Consent. Ann Arbor: University of Michigan Press, 1969. Originally suggested by John Caldwell Calhoun in his "Speech on the Admission of California - and the General State of the Union" (March 4, 1850). In John C. Calhoun, Union and Liberty. Indianapolis: Liberty Fund, 1992, pp. 571-601 
in place, they are difficult to remove, and the damage to the rival can be substantial. On the other hand, the choice based tax instruments, as it is an individualized almost custom made package for each particular set of decisions makes, it is very difficult for rivals to effectively intervene as they can in the Pigouvian scenario. Hence, from the point of view of preventing rent seeking, the choice based approach is preferable, yet again the federal level has a very small role to play, only at most a supervisory one, probably to be excercised by the respective court of audit of that federal jurisdiction.

5. On the issue of fairness with respect to any form of environmental policy, it is difficult in that for instance in the European Union the preferences of voters with respect to such issues as personal income growth, employment or environmental improvements tend to diverge substantially, typically in a north south divide, with the northern Member States emphasizing ecological issues at the expense of growth, the southern states expressing the reversed preference. What is fair, of course, is basically an empirical issue. Tax policies have to be in sync with voters' preferences, and if they are not, they are considered unfair. Issues of fairness cannot be deductively determined, they are largely in empirical issue. ${ }^{14}$ From this point of view, the federal level of government is ill prepared to ensure fairness in taxation with respect to either form of ecological taxation here discussed. However, in addition, the choice based form of ecological taxation requires the knowledge of many local aspects which cannot necessarily be assumed to be fairly represented at the federal level of government. At the federal level of government, local legislators such as those sitting in the European Parliament, tend to bundle different concerns together so as to accomplish a maximum for their particular district, but the end result to the outsider often looks bizarre. From the point of view of the fairness criterion it seems that the federal level of government is ill-suited for either form of taxation.

6. The issue of whether the state level of government can efficiently discharge either of the two policy scenarioes discussed depends a lot on the constitution of the particular state with respect to ecological circumstaces. Remarkably, just as of this writing, Poland has re-constituted itself into a set of reletavily independent provinces from a centrally inspired system of centrally directed departments, and these provinces to a certain extent follow geographical and ecological conditions, with Silesia, Pommerania and Allenstein-Ermland being reconstituted. However, many ecological problems defy the possibilities of states that have to operate within the boundaries that they have historically inherited. Here, it is often necessary that different states often from different Member States of a federation join together insolving a particular ecological problem that they face together, but which is not important enough to really reach the agenda of their respective federal entity. This can be effected, in the European context, through an agressive application of the subsidiarity principle ${ }^{15}$. If a state does not

14 See Gustav Schmoller, "The Idea of Justice in Political Economy", in: Annals of the American Academy of Political and Social Sciences, IV, 1908, pp. 697-737

15 See Jürgen Backhaus, "Subsidiarity and Ecologically Based Taxation: An Essay on Public Choice From a European Point of View. Public Choice 88, 1996 
want to go it alone with a specific Pigouvian tax regime, it has only a very small role to play, as the federal level of government will insist on tax harmonization. However, with respect to the choice based ecological tax approach, states have much more of a role to play, in particular with respect to initiating and facilitating such regimes which have to be implemented at a lower level.

7. As we look at administrative feasibility, however, it appears that both systems can be readily implemented by the states, as they tend to have the most effective administrative bodies. However, the states will also suffer the adverse repercussions of the Pigouvain tax scenario, while on the other hand they will be able to reap some of the benefits of the choice based approach. This will be the case, because they will suddenly share in the tax revenue thus generated. Civil servants in the tax service necessarily emphasize the fecundity of a particular tax, and therefore devote most of their attention to those taxes that yield sub-stantial revenue. In this sense, the choice based approach enjoys a feasibility advantage, as it is more congenial to the ethics of a tax officer to generate revenues with a minimum of excess burden and conceivably a technological tax improvement earned on the side.

8. At the state level, the Pigouvian tax regime cannot be expected to flexibly respond to changing economic or ecological conditions by itself in terms of a self-enforcing tax regime. If, for instance, the state levies a tax per kilowatt hour of electricity production, increased economic activity will simply translate into increased demand and a substantial shifting of the tax onto the user, in the case of industrial users probably further even onto the customers, the ecological effect will be small. On the other hand, the choice based system working with tax credits quickly translates changing economic decisions into the relevant investment decision calculus: if in the same example, increased demand prompts a capacity expansion, technology choice will be directly perfected in the desired direction to achieve the environmental goal. Typically, the states have jurisdiction of both the tax administration and the environmental regulatory bodies; for instance in the Federal Republic of Germany each of the sixteen states has its own ministry of finance and one ministry designated for environmental affairs. Hence, the too prominent administrative structure required for the implimentation of the choice based proposal is, indeed, present at the state level.

9. If the Pigouvian tax regime is introduced at the state level, it will be difficult to reflect the state electorate's preferences with respect to environmental issues in the level of the unit charges. The states compete among each other for the siting of industries, and, for instance in the case of electricity generation, it is easy to shift production from one state to the other, as essentially all Europe is interconnected and distance only imposes costs in terms of losses and transportation. The choice based regime working with tax credits, however, is better suited to reflect the different voters'

See Roger van den Bergh, Michael Faure and Jürgen Lefevre, "The Subsidiarity Principle in European Environmental Law: An Economic Analysis", in: Erling Eide and Roger van den Bergh (eds.), Law and Economics of the Environment, Oslo: Juridisk Forlag, 1996, pp. 121-166 
preferences, since in the implementation of these policies both the environmental authority and the fiscal authority can vary the standards which they apply in using their discretion. A state particularly eager to push environmentally compatible production technologies can take, through its environmental authority, an active role, even suggesting particular technologies and supporting feasibility studies, thereby facilitating the grant of the tax credit.

10. From the point of view of fairness, the state is better positioned to translate voters' preferences into policies with respect to either tax regime, as in a federation the notions of fairness with respect to environmental issues tend to be much more different than in a smaller entity. But this is a relative statement only. With respect to the two different tax regimes, a more specific statement is possible. The typical Pigouvian tax regime as per unit charges can be extra-ordinarily regressive, burdening those with the least elastic demand curve for the product in question. And this group will necessarily include a large number of those who, by whichever criterion is used, are considered worse off in that particular society and should therefore benefit from an application of the fairness principle to the particular policy in question. On the other hand, the choice based regime does not have these regressive effects, and it is therefore not open to this criticism from the point of view of fairness.

11. At the regional or local level, with respect to efficiently implementing either one of the two tax regimes, substantial differences appear. The smaller the jurisdiction in question, the more difficult it becomes to conduct an own policy if the instrument at hand is the Pigouvian tax regime. Competition among jurisdictions will drive the ecological charges downwards in terms of some kind of Dela Warization process, making the instrument difficult to handle at the local level. Also in the implemen-tation literature, implementation deficits ${ }^{16}$ tend to be concentrated at the lower levels of government and in the smaller states. For instance, Germany's substantial implementation deficit with respect to European Union legislation owes much to the complicated structure of the federation, since the federal government typically cannot enact the legislation in question by itself but needs the co-operation of the states, some-times the municipalities as well. Hence, for the Pigouvian tax regime the regional and local governments can hardly be seen as the appropriate jurisdictions to carry out the policy. This is different for the choice based regime, since here a possible implementation deficit would work to the disadvantage of the company that wants to apply the tax credit to its revenues. Hence, the regime is self-enforcing and the problem just sketched does not appear.

12. For reasons similar to those given under 11, the feasibility of the Pigouvian tax regime at the regional or local level is questionable. Obviously, since the regime is so simple, it can be easily monitored and it can also be implemented if the admini-strative will is present. However, since the regime may run counter to the interests at play at the local or regional level, the aforementioned implementation deficit will arise, and here lies the feasibility problem. On the other hand, the choice based system is necessarily deeply anchored in the local community, and hence will be utorly feasible, since all the 
parties involved derive a gain of some sort. The various producers improve their production possibilities, the tax collecting authority ultimately reaps higher revenue and in any event broadens its tax base, and the environmental authority, from the very start of the implementation of the technology, is aware of all the technological details and hence able to monitor the respective activities actively, therefore being able to easily discharging its duties.

13. Changing circumstances can be particularly trying at the local level, and a rigid regime such as the Pigouvian one can bring about substantial friction loss. It has to be inflexible since otherwise it would be easily undermined by interest groups, which operate most effectively at the highest level of government, i.e. the federal level. The choice based approach, on the other hand, does allow for flexible responses, most of which are built in the very proposal. The tax credit, for instance, can only be applied against income actually earned. Hence, whatever delays there may occur in construction or otherwise in the implementation of the project do not affect the community much, as the company in question has a maximum incentive to implement the ecologically friendly project in order to earn the tax credit. For instance, if labour is in abundant supply in a macro-economic slump, the project will be completed faster, and part of the abundant labour supply will be absorbed in the project: on the other hand, if there is a shortage in the labour market, the project may be delayed, but the delay will not work out cyclically, rather anti-cyclically. The tax credit itself has an equilibrating function.

14. At the local level, the communication lines are so short that behaviour by government agencies that is irresponsive to the sentiment of the population can meet with drastic disapproval, even outright obstruction. The implementing agency of the Pigouvian tax regime at the local or regional level is confronted by a substantial problem, hence the aforementioned implementation deficit. On the other hand, the choice based system allows for so much information to be filtered into the process before the investment has actually been made that, unless circumstances change dramatically, the project should always be highly responsive to different local demands. In the example sketched above, it was shown to be responsive to changes in weather conditions, conditions of the river, seasonal variations and the like.

15. At the local level, the most important issue of equity or fairness is the provision of the basic needs (Daseinsvorsorge), and it is here where the Pigouvian regime substantially encumbers the companies charged with the provision of local needs, while the choice based system can allow for a far reaching consideration of local circumstances, it actually is based on the requirement. to use these data as an input.

16. Now we are turning to the possibility or organizing jurisdictions in such a way, that while they are competing, they may actually overlap and be functionally defined as opposed to territorially. This is highly important from the point of view of the environment, since many people engage in activities that are relevant to the environment who live in different territorially based jurisdictions, while in each one of these jurisdictions, only very few engage in the relevant activity. If you are a dentist, for instance, you necessarily have to use some material that can be toxic if inadvertantly dumped into the environment such as into water. It would make little sense to require 
every local jurisdiction to oversee the use of these materials, as for all intents and purposes only dentists as a group constitute, in this example, the major cause for concern. Hence, the medieval principle of organizing professions as estates can be relied upon, in this case creating a jurisdiction over all practicing dentists. The regime with respect to their environmentally relevant behaviour would then have to be administered by this jurisdiction of, say, European dentists, and again we can think of two variations of our two regimes, on the one hand a per unit charge on the use of the material in question, on the other hand a system of tax credits depending upon the choice of technology and certification used in the respective practice. ${ }^{17}$ From the point of view of economic efficiency, the FOCJ (Functional Overlapping Competing Jurisdictions) are a direct institutional translation of the standard public goods model. Hence, their relationships to the concept of economic efficiency is immediate. However, within these FOCJ the two different tax regimes can still be at issue, and it is immediately clear that the Pigouvian regime may well be decided upon by a majority of constituants, such as the dentists, depending upon the demand schedule of their respective customers. Old dentists will be interested in and defending their old technology and they would prefer the Pigouvian charge, while newly graduated dentists would be more prown to implementing new technologies, since the technology used it necessarily tied to the human capital, and increasingly so over time. Hence, from the point of view of economic efficiency, the choice between the two regimes under conditions of FOCJ needs to be discussed with the appropriate social discount rate in mind. Basically, the choice based system will be more innovative and therefore dynamically more efficient than the Pigouvian regime.

17. The feasibility of implementing FOCJ depends first of all on the constitutional circumstances of each Member State. It is not by chance that Swiss authors suggest this particular proposal, since the basically medieval concept is still somewhat alive in the Helvetian confederation. However, the wisdom of the concept should not be underestimated. The change from functional to territorial organization in the Holy Roman empire ultimately led to the Thirty Years War, one of the big desasters in Central European history. Hence, it makes sense to re-think the constitutional pattern of organization, and to tie this into modern economic theory. Issues of feasibility need to be discussed for each particular suggestion made. For instance, it is quite possible to organize, on a European scale, all dentists and then regulate their environmentally relevant behaviour. Here, we can again look at the two tax regimes, and it will be obvious that the per unit charge will be more feasible if the customer is a national health service and simply absorbs the entire tax. The environmental impact will be next to nihil. On the other hand, if the dentists themselves operate in a competitive environment, they may be prone to technological innovation, and here the effect would be very different indeed. Hence, from that point of view, the choice based appraoch appears to be superior.

17 For the details on this scheme, see Bruno S. Frey and Reiner Eichenberger, "FOCJ; Creating a Single European Market for Governments", in: Dieter Schmidtchen and Robert Cooter (eds.), Constitutional Law and Economics of the European Union, Cheltenham: Edward Elgar, 1997, pp. 195-215 
18. The issue of flexibility needs to be discussed in terms of two different aspects. On the one hand, since interests are so well defined in terms of functional purposes, the entire jurisdiction can be pictured as being extremely alert with respect to the issues that confront this particular group. On the other hand, it may seem utterly inert as a lot of experience tends to be build into its standard reactions, certainly over time. If the group is highly functionally organized, it will have intricate ceremonies with end based reward systems and very little flexibility in its rules, while very wide areas of discretion with respect to the material issues. ${ }^{18}$ Hence, what may appear inflexible may indeed be highly flexible in providing functional responses. In implementing a Pigouvian regime, the FOCJ are in much better shape than the territorially based jurisdictions, because they do have the respective information to set efficient rates. How they solve the problem of innovation within their own jurisdiction, the problem mentioned under 16 , depends very much on their internal structure and on the extent to which they have to confront competitive challenges. For instance, if in the case of the dentists the customers are organized, at least in some countries, through national health programs, technology choice will be seriously affected. This leads us to conclude that the feasibility of implementing this program depends very much on institutional circumstances, time and place.

19. The issue of political responsibility acquires a totally different dimension in the context of FOCJ, since we can no longer talk about an Athenasian polis with all its (independently wealthy) citizens gathering in the market place, if the members of the FOCJ can be widely scattered and need not necessarily come into personal contact one with the other on a regular basis. Here, political responsibility has to be discussed in terms of group democracy, the ability of the group leadership to avoid

Michels' Iron Law of Oligarchy and to be responsive to the needs of the base. This will depend much on the voting mechanisms used, and public choice literature provides a wealth of possibilities to solve that particular problem, the demand revealing process being one of them that comes immediately to mind. Here, the choice of either one of the mechanisms will be taken with much more information as an input than in any of the other scenario's sketched. However, monitoring the choice based process becomes much simpler in the context of FOCJ, since new information on technological possibilities and pitfalls will be constantly available and floating in the networks of that particular profession or group. Hence, the FOCJ approach does allow for substantial improvement in enhancing political responsibility of whichever tax regime is to be chosen.

20. One of the interesting aspects of the FOCJ approach is that issues of fairness can no longer be discussed in terms of equity. If you focuss on a particular group which is a composition of small subsets of different societies, the equity notions that prevail in any one particular society can no longer be part of the common ideology of that particular group that you have organized as a FOCJ. This means that fairness will 
have to be discussed not in terms of material outcomes but in terms of procedural rules. It does not strike me as obvious that the two regimes differ on this particular criterium.

\section{Concluding remarks}

The answer to the question noted in the title of this paper then becomes clear and simple. An effective ecological tax is a tax credit on personal or corporate income taxes upon certifications of an ecological improvement scheme. The tax credit kicks in when the scheme is being made effective. The operation of the scheme depends soley on the co-operations of tax payers, it requires no additional information on the part of necessarily underinformed public authorities. Interestingly, there is a new and peculiar double dividend in the sense that next to an ecological improvement, there is a new revenue stream for government. 


\section{Literature}

Benito Arruñada, "In the Economics of Notaries", European Journal of Law and Economics, 3 (1), 1996, pp. 5-38

Backhaus, J., "Subsidiarity and Ecologically Based Taxation: Aspirations and Options", in: Sabine Urban, Europe in Progress, Wiesbaden: Gabler, 1995, pp. 223-264.

Roger van den Bergh, Michael Faure and Jürgen Lefevre, "The Subsidiarity Principle in European Environmental Law: An Economic Analysis", in: Erling Eide and Roger van den Bergh (eds.), Law and Economics of the Environment, Oslo: Juridisk Forlag, 1996, pp. 121166

Bovenberg, L. and R. de Mooij, "Environmental Levies and Distortionary Taxation. American Economic Review, vol. 84, no. 4, September, 1994, pp. 1085-1089.

Buchanan, J.M., Cost and Choice: An Inquiry in Economic Theory. Chicago: Markham, 1969.

James M. Buchanan and Gordon Tullock, The Calculus of Consent. Ann Arbor: University of Michigan Press.

Bruno S. Frey and Reiner Eichenberger, "FOCJ; Creating a Single European Market for Governments", in: Dieter Schmidtchen and Robert Cooter (eds.), Constitutional Law and Economics of the European Union, Cheltenham: Edward Elgar, 1997, pp. 195-215

Goulder, L., "Environmental Taxation and the "Double Dividend". A Reader's Guide". Paper presented at the International Institute of Public Finance, 50th congress, Cambridge, Massachussets, August 23-25, 1994, also NBER working paper, nr. 4896.

Pearce, D., "The Role of Carbon Taxes in Adjusting to Global Warming”, Economic Journal, vol. 101, 1991, pp. 938-948.

A.C. Pigou, Socialism vs. Capitalism, London: McMillan, 1947, pp. 40-44

Gustav Schmoller, "The Idea of Justice in Political Economy", in: Annals of the American Academy of Political and Social Sciences, IV, 1908, pp. 697-737

Schneider, F. and Volkert J., "Die Realisierung ökologisch-orientierter Wirtschaftspolitik - eine Unmöglichkeit? Überlegungen aus Sicht der Neuen Politischen Ökonomie". Arbeitspapier: 9611, Juli 1996.

Frederick Seitz, “A Major Deception on 'Global Warming"', Wall Street Journal Europe, June 20, 1996 and "Letters to the Editor": "Cover-up in the Greenhouse?", August 6, 1996.

Adam Smith, The Wealth of Nation, book 5, chapter 2, part 2, section 2. London: Dent, 1971, II, p. 306. 
Joseph Stiglitz, Economics of the Public Sector, New York: Norton

Gerd Winter, Das Vollzugsdefizit im Wasserrecht. Berlin: Schmidt, 1975 